\title{
Do China's Manufacturing Cross-Border Mergers and Acquisitions Enhance Its Management Innovation Capabilities?
}

\author{
Yunyun LUO* \\ School of Economics and Management, Beijing Jiaotong University, Beijing 100044, China \\ Email: 1044547994@qq.com
}

\begin{abstract}
Keywords: cross-border mergers and acquisitions, management innovation, manufacturing
Abstract. In recent years, the rapid growth of overseas mergers and acquisitions of emerging market companies represented by Chinese companies has shown a strong incentive to catch up with innovation. From the perspective of management, this paper studies the impact of cross-border mergers and acquisitions of Chinese enterprises on management innovation capabilities. Based on the data of cross-border mergers and acquisitions of listed Chinese manufacturing companies from 2009 to 2018, this paper uses 2015 as the initial investment year for cross-border mergers and acquisitions, and uses the PSM-DID method to study the impact of cross-border mergers and acquisitions on parent company management innovation. The study found that, in general, crossborder mergers and acquisitions in the manufacturing industry have significantly improved the ability to manage and innovate enterprises. Compared with state-owned enterprises, cross-border mergers and acquisitions have a more significant impact on the management and innovation capabilities of private enterprises. This article provides a new perspective for clarifying the impact of cross-border mergers and acquisitions on corporate management innovation, and has certain inspirational value for the practice of cross-border mergers and acquisitions in emerging market companies.
\end{abstract}

\section{Introduction}

Innovation is the key for enterprises to maintain their competitive advantages, and it is also an important driving force for sustained economic growth. The 18th National Congress of the Communist Party of China has explicitly proposed the implementation of an innovation-driven development strategy, emphasizing that technological innovation is a strategic support for improving social productivity and comprehensive national strength, and must be placed at the core of the country's overall development [1]. Compared with developed countries, Chinese companies have certain gaps in their financial strength, technological level, innovation environment, and national support. Moreover, Chinese companies have a relatively short development history. Application products that are developed from the foundation are not suitable for late development. Advantaged Chinese companies. Therefore, most Chinese companies adopt cross-border mergers and acquisitions to directly obtain advanced foreign innovation results and improve their own innovation capabilities [2]. According to the data in the "Statistical Bulletin on China's Outward Foreign Direct Investment" issued by the Ministry of Commerce, 2016 was the most active year for Chinese companies' overseas M \& A. With 765 overseas investment and M \& A projects implemented, the actual total transaction amounted to USD 135.33 billion, forming the overseas of Chinese enterprises. The wave of $\mathrm{M} \& \mathrm{~A}$ investment.

Innovation can bring vitality to enterprises and play an important role in their sustainable development. Daft [3] decomposes enterprise innovation activities into two parts: technological innovation and management innovation. From the rapid development experience of Japanese enterprises through management innovation practices such as total quality management and lean production, compared with technological innovation, management innovation can also promote 
enterprises to build sustainable competitive advantages. Management innovation can optimize the allocation of resources in the decision-making layer, management layer and operation layer of an enterprise and improve the efficiency of the enterprise. It is a more effective new resource integration paradigm refined and created by the enterprise in the process of management. Management innovation can improve the management efficiency of enterprises and better achieve their development goals [4].

The research results of scholars show that cross-border mergers and acquisitions have a certain impact on corporate management innovation. On the one hand, cross-border mergers and acquisitions through the integration of human resources, corporate culture, and synergy to improve the team's management capabilities [5-6]; on the other hand, cross-border mergers and acquisitions have expanded production and sales capabilities. The scale effect of mergers and acquisitions can effectively improve the overall management innovation level of enterprises after mergers and acquisitions [7]. However, the existing research tends to use management theory to explain the mechanism. It is mainly based on cases and lacks empirical analysis. In fact, as the number of crossborder mergers and acquisitions increases, the data available for analysis increases, creating conditions for empirical analysis. The overall goal of this article is to build a management innovation capability index from a management perspective and determine the impact of Chinese cross-border mergers and acquisitions on business management innovation capabilities. Under the current background of China's economic structural transformation and active overseas mergers and acquisitions, the research in this paper can provide useful policy inspiration for the further implementation of the "going out" strategy.

\section{Theoretical Analysis}

The impact of cross-border mergers and acquisitions on corporate management innovation capabilities is mainly through the following channels: First, the integration of human resources. In the final analysis, the management of people and the management of people, the differences in the human resources of the merged and acquired enterprises will necessarily require the merger and acquisition of enterprises to integrate human resources. After cross-border mergers and acquisitions, companies need to promote the exchange and learning of talents, learn from each other, improve the incentive mechanism, force companies to optimize existing management models and systems, and promote the improvement of corporate management innovation capabilities. Second, the integration of corporate culture. The management of Chinese enterprises is mainly based on the traditional Chinese management culture, emphasizing inclusiveness and humanism [8]. Western management is based on science. The complementarity of management culture can promote the improvement of management innovation capabilities of enterprises. Third, Cross-border mergers and acquisitions often have the function of opening up markets. The scale effect brought by the expansion of market shares places higher requirements on the management capabilities of enterprises, forcing the improvement of management innovation capabilities of enterprises.

\section{Empirical Analysis}

This article mainly studies the impact of cross-border mergers and acquisitions of Chinese companies on management innovation capabilities. The research objects are mainly listed companies in the manufacturing industry. The time span is from 2009 to 2018 . This is mainly because the activeness of $\mathrm{M} \& \mathrm{~A}$ investment of listed companies is much higher than that of other domestic enterprises, and it is the main force of Chinese companies' overseas M \& A. Overseas M \& A transactions also mainly occurred after the 2008 financial crisis. In addition, listed companies have relatively high innovation capabilities, and $\mathrm{RD}$ expenditures account for more than one-third of national companies' RD. It is representative to select a sample of listed companies to examine the 
impact of overseas mergers and acquisitions on corporate innovation. Moreover, manufacturing industry is the main industry involved in cross-border mergers and acquisitions of Chinese enterprises, and it also occupies an important share in China's national economy. Therefore, this article mainly discusses the impact of cross-border mergers and acquisitions in manufacturing industry on corporate management innovation capabilities. Corporate cross-border mergers and acquisitions are not random. Only those companies with productivity and technological advantages will choose cross-border mergers and acquisitions investment. The direct use of OLS estimation may lead to biased estimation results. Therefore, overseas mergers and acquisitions are regarded as a quasi-natural experiment. PSM (Preference Score Matching) and DID (Double Difference) are used to evaluate the innovation performance of overseas mergers and acquisitions.

Management Innovation Ability (INN). The research on management innovation can begin with the analysis of management innovation activities. Management innovation activities mainly exist in the management activities of enterprises. Starting from the input and output indicators of management activities and their performance indicators, a set of indicator systems that can reflect the costs, revenues and effects of enterprises can be established. This article mainly uses the contribution of management expenses, that is, the ratio of main business income to management expenses [9]. The data comes from the financial database of WIND listed companies.

Cross-border M \& A (MA). Corporate cross-border mergers and acquisitions are represented by dummy variables, which mainly use Chinese listed companies' cross-border mergers and acquisitions to determine 0 or 1.1. 1 represents the sample of the experimental group where crossborder mergers and acquisitions occurred, and 0 is the control group sample where no cross-border mergers and acquisitions occurred. The data mainly comes from Zero2IPO database. Cross-border mergers and acquisitions completed by listed manufacturing companies from 2009 to 2018 are selected. Samples with less than $10 \%$ of the merger and acquisition shares are excluded. The first cross-border merger and acquisition is selected. For companies that have multiple cross-border mergers and acquisitions in the same year. Retain the largest transaction size. The sample of the control group is the companies that are not involved in cross-border mergers and acquisitions among listed companies in the manufacturing industry, and the companies that exclude ST are excluded.

Control variables. M \& A experience (age of the enterprise), asset size, number of employees, etc. will have a certain impact on the management innovation of the enterprise, which is expressed by AGE, ASSET, NUM, respectively.

\subsection{Descriptive statistics}

The sample data in this article comes from the data of listed companies in Guotai'an database and the data of cross-border mergers and acquisitions in Zero2IPO database. The data in the database of cross-border mergers and acquisitions is matched with the data of listed companies. It serves as the experimental group, and those without cross-border mergers and acquisitions serve as the control group. From the data obtained, the highest number of cross-border mergers and acquisitions of manufacturing companies from 2009 to 2018 was 30 in 2015. Therefore, this article uses 2015 as the initial investment year for cross-border mergers and acquisitions, and estimates the impact of crossborder mergers and acquisitions on management innovation capabilities in subsequent years. . This paper first studies the impact of cross-border mergers and acquisitions on the second year, and selects 92 companies as the control group. 
Table 1 Descriptive statistics.

\begin{tabular}{llllll}
\hline & N & Minimum & Maximum & Mean & $\begin{array}{l}\text { Standard } \\
\text { deviation }\end{array}$ \\
\hline INN & 74 & 0.0174 & 0.5318 & 0.115674 & 0.0946103 \\
AGE & 74 & 7 & 36 & 19.81 & 6.478 \\
NUM & 74 & 46 & 64817 & 5208.23 & 8236.646 \\
ASSET & 74 & 51489647 & 120411751686 & 9318207397 & 17560305205 \\
\hline
\end{tabular}

It can be seen from Table 1 that the highest management innovation capacity of enterprises is 0.5318 and the lowest is 0.0174 . There are certain differences, and there are certain gaps in the age and asset size of companies, indicating that cross-border mergers and acquisitions may have selfselection effects. Need to use PSM-DID for analysis.

\subsection{Result analysis}

The logic model was used to estimate the propensity scores for overseas mergers and acquisitions, and the nearest neighbor matching method was used to match the sample of the processing group (overseas mergers) to the appropriate control group. The results of the matching balance condition test report are shown in Table 2. From the results of the $T$ test, there was no significant difference between the treatment group and the control group after matching, indicating that the nearest neighbor matching has achieved better results. Being able to control the self-selection effect of the sample shows that our matching results are reliable and the matching variables selected are more reasonable.

Estimated by the PSM-DID method, the ATT is 0.059 , the $\mathrm{T}$ value is 0.098 , and it is significant at the level of $10 \%$, indicating that cross-border mergers and acquisitions indeed promote the improvement of corporate management innovation capabilities. The enterprises were further divided into state-owned enterprises and private enterprises. As a result, the ATT of the state-owned enterprises was 0.023 , the T value was not significant, and the ATT of the private enterprises was 0.061 , which was significant at the level of $10 \%$. The effect is even more significant in private enterprises.

Table T-test for PSM matching samples.

\begin{tabular}{lcccc}
\hline Variable & \multicolumn{2}{c}{ Mean } & \multicolumn{2}{c}{ t test } \\
& Processing group & Control group & t value & p-value \\
\hline INN & 0.098 & 0.150 & 1.76 & 0.1851 \\
AGE & 19.214 & 18.941 & 0.20 & 0.8396 \\
NUM & 5419.286 & 2945.150 & 1.74 & 0.1892 \\
ASSET & $5.4 \mathrm{e}+09$ & $3.4 \mathrm{e}+09$ & 1.65 & 0.1059 \\
\hline
\end{tabular}

\section{Conclusion}

Cross-border mergers and acquisitions in the manufacturing industry have significantly enhanced the ability to manage and innovate in enterprises. Compared with state-owned enterprises, crossborder mergers and acquisitions have a more significant impact on the ability to manage and innovate in private enterprises. Based on this, this article draws the following policy implications: First, from the perspective of the enterprise, it is necessary to continuously improve the ability of the enterprise to adjust its management systems and methods. Enterprises in cross-border mergers and acquisitions can improve their management and adjustment capabilities through system reform and improvement of human resource structure to adapt to the integration of enterprises after mergers and acquisitions. At the same time, state-owned enterprises need to accelerate the pace of change and 
improve their management innovation capabilities. Second, from the perspective of government regulation, encourage cross-border mergers and acquisitions while increasing supervision. In recent years, capital outflows have accelerated. On the one hand, we must strive to ensure that cross-border mergers and acquisitions serve the real economy. On the other hand, we must also pay attention to preventing financial risks, strengthen the management of project approvals, improve the quality and efficiency of approvals, and increase penalties.

\section{Acknowledgment}

I would like to thank my guidance teacher, Wei Bu. Under his careful guidance, my thesis was completed. My teacher's rich professional knowledge, rigorous research attitude, pragmatic work style and sincere care for students have left a deep impression on me, and will also benefit me greatly.

\section{References}

[1] G M Xian and X N Ming. Cross Broad Merger and Innovation of Acquiring Firms Journal of Financial Research, 2018(8), p 155 171

[2] Y L Cao and X Y Li. The Effect of Technology Innovation Capability Enhancement of Crossborder M \& A from the Perspective of the Global Innovation Chain Xinjiang Social Sciences, 2018(3), p 42 50

[3] R L Daft. A Dual Core Model of Organizational Innovation Academy of Management Journal, 1978(21), p 193 210

[4] S W Jing and Z W Niu. Quantitative Research on the Contribution of Management Innovation to Enterprise Innovation Science \& Technology Progress and Policy, 2015(32), p 105 109

[5] Y Z Tang, Z Z Wang and X P Wang. An Analytical Framework of the Cultural Integration of Cross-border $M \& A-O n$ the Cultural Integration of Cross-border M \& A of Chinese Enterprises Economic Management, 2008(10), p 24 29

[6] J H Wang. Human Resources Management Strategy of Enterprise M \& A-Talking from the Merger and Acquisition of Lenovo Group and IBM PC Economic Management, 2005(7), p 86 89

[7] S H Ye, K Y Wang and Y P Sun. A Study on the Impact of Cross-border M \& A on the Competitiveness of Host Country Enterprises: An Empirical Analysis Based on the Data of Chinese Manufacturing Enterprises International trade issues, 2016(1), p50 59

[8] D S Su. On the Integration and Innovation of Eastern and Western Management Academic Research, 2002

$(5)$

39 45

[9] T N Wang and Y M Tu. Impact of technological innovation ability on enterprise performance under the management innovation ability adjustment Technology Economy, 2012(10), p25 32 